\title{
MIXTECOS EN BAJA CALIFORNIA: EL CASO DE SAN QUINTÍN
}

\author{
Por \\ Everardo Garduño*
}

\begin{abstract}
RESUMEN
En este trabajo ${ }^{1}$ se presentan los múltiples aspectos por los que el valle de San Quintín es un lugar propicio para la horticultura; pero sobre todo el por qué es un polo de atracción de flujos migratorios provenientes, en su mayoría, de la Mixteca oaxaqueña.

El autor hace un análisis de las condiciones de vida y trabajo de todos los migrantes indígenas en San Quintín, de su proceso de aculturación y de su integración social.
\end{abstract}

\begin{abstract}
In this work are shown several aspects for which the San Quintin valley is an ideal land for horticulture; but above all, the main reason why it has become a pole of attraction for the migrating masses, specially those from the mixteca region of Oaxaca.

The author also makes an analysis of the conditions under which the indians migrants live and work in the San Quintin valley; their process of cultural assimilation and their social integration.
\end{abstract}

\section{INTRODUCCIÓN}

Aunque el primer enganche de jornaleros indígenas para trabajar en la producción agrícola de Baja California data de 1959 , no fue sino hasta la década de los setenta cuando el valle de San Quintín, ubicado al sur de la ciudad de Ensenada, Baja California, se convirtió en uno de los polos atractores de fuerza de trabajo estacional más importantes del país debido al auge de la producción hortícola en esa región.

Desde entonces a la fecha, cada verano San Quintín recibe la visita de un contingente aproximado de 30 mil migrantes indígenas, que representan un poco más del doble de la población permanente en la región (INI,1987).

* Sociólogo, investigador del Museo Regional Universitario de la UABC.

1 Este trabajo se desprende de la investigación realizada en 1987 por el Instituto Nacional Indigenista en Baja California "Mixtecos en Baja Califomia: el casode San Quintín", a cargo de Everardo Garduño, Efraín García y Patricia Morán. 
Este flujo migratorio posee una composición étnica variada, pero mayoritariamente mixteca. De acuerdo a los resultados de nuestra investigación, a este valle acude un flujo migratorio que en su $63 \%$ es de origen mixteco, en un $20 \%$ zapoteco, en un $13 \%$ triqui, y el $4 \%$ restante está compuesto por nahuas, tarahumaras y tarascos.

Por esta razón el presente artículo ha sido titulado "Mixtecos en Baja California. El caso de San Quintín", aun cuando en el apartado referente a las condiciones de vida y de trabajo se describen las condiciones en que viven y laboran todos los jornaleros indígenas en la región, sean mixtecos o no.

La explicación de los movimientos migratorios ha sido abordada desde dos puntos de vista: la visión histórico-estructural y la visión étnico-cultural.

La primera encuentra las causas de la migración en los movimientos del capital; mientras que la segunda basa sus determinantes en las decisiciones personales o de grupo de los propios migrantes.

Se considera que todo estudio sobre migración étnica, debe tomar en cuenta tanto sus determinantes económicas generales como las estrategias particulares que se establecen grupalmente para la supervivencia; esto para identificar el papel que juega la cultura del grupo en la reproducción, tanto de la fuerza de trabajo como de la etnia, ya que se considera que los grupos étnicos poseen especificidades culturales en sus estrategias de subsistencia.

Esta forma de abordar el estudio permite al investigador conocer, desde un punto de vista más completo, las formas particulares que los grupos indígenas implementan para sobrevivir ante la subordinación a que se ven sujetos por el modo de producción dominante, que los obliga a vender su fuerza de trabajo en condiciones desventajosas.

Desde el punto de vista estructural, el origen de esta migración se puede encontrar en factores económicos de expulsión y de atracción, lo que hace del fenómeno un tema ubicable dentro de la economía; sin embargo, por las características de las condiciones de vida y de trabajo en las que se reproducen estos jornaleros como fuerza laboral, exigen del tema un diagnóstico social; y más aún, por tratarse de fuerza de trabajo indígena, es decir, con un contenido étnico específico, el tema se ubica además en la dimensión antropológica-cultural.

Este artículo, síntesis de una investigación más amplia que a manera de estudio preliminar se estructura sobre estos tres ejes: el aspecto económico, el aspecto social y el aspecto cultural, se centra más detenidamente en la descripción de las condiciones de vida de estos indígenas en la región de San Quintín, independientemente de 
su origen étnico y en el estudio del proceso de aculturación, experimentado por aquellos jornaleros de origen mixteco.

La larga historia de colonización y despojo de las comunidades indígenas explica el por qué la mayoría de sus habintates están ubicados en terrenos quebrados, desérticos, o bien en tierras poco aptas para la agricultura. La mayoría de estas comunidades se localizan en el sur del país, en donde distintos grupos étnicos recurren frecuentemente a la migración en la búsqueda de alternativas de ingreso. De esa región de México, Oaxaca es el estado que mayor población expulsa, y de ésta, la población mixteca es la de mayor presencia en el noroeste.

Esta etnia, por su tradición migratoria, ha sido calificada por algunos como una cultura migrante, porque a lo largo de su historia se ha dirigido hacia distintos polos de desarrollo. Sin embargo, tal parece que en los últimos años el movimiento migratorio, no sólo el de mixtecos, ha cambiado el medio urbano como lugar de destino, y se ha dirigido hacia las zonas rurales de reciente impulso. Esto se debe fundamentalmente al papel agroexportador que el estado ha asignado a los distritos de riego cercanos a la frontera norte, a los que acuden empresas transnacionales que encuentran un elevado rendimiento en la tierra, bajos costos de producción y una ganancia extraordinaria procedente del control simultáneo que tienen sobre la producción hortícola nacional y el mercado internacional de este producto.

El mecanismo por medio del cual los productores incrementan la productividad de la tierra es a través de un elevado desarrollo tecnológico, pero también con la explotación excesiva de los jornaleros indígenas, ya que sustraen beneficios de la docilidad de la mano de obra indígena. $Y$ aun cuando la estrategia para elevar la productividad de la tierra depende de la capacidad que tenga cada productor para incorporar a su proceso productivo los avances tecnológicos, se puede afirmar que todos ellos encuentran una rica fuente de ingresos en la expoliación de la fuerza de trabajo, al negar a sus trabajadores indígenas los derechos laborales más elementales establecidos por la Ley Federal del Trabajo y que sí otorgan a los trabajadores mestizos de origen sinaloense, empleados para la selección y empaque del producto.

Las deplorables condiciones de vida en las que son alojados los jornaleros indígenas migrantes arrojan un cuadro de morbi-mortalidad en la región realmente alarmante; a través de él se puede observar que las condiciones insalubres son la causa principal de enfermedad (43\%), y de muerte (46\%)(INI, 1987).

En lo que respecta a las condiciones de trabajo, destacan las extenuantes jornadas de 10 a 11 horas, el escamoteo de los pases del seguro social; 
la situación desventajosa de la mujer y el trabajo infantil, así como la anulación de los derechos contemplados en los artículos $64,69,77,80,87$ y 117 de la Ley Federal del Trabajo. ${ }^{2}$

Desde nuestro punto de vista, los migrantes indígenas son campesinos que viven en el marco de un capitalismo dependiente que si bien tiende por una parte a proletarizarlos, por otra mantiene sus espacios y mecanismos tradicionales de supervivencia, al encontrar en la economía campesina una especie de subsidio de la reproducción de la fuerza de trabajo estacional. Así también, desde la perspectiva de la aculturación, consideramos que estos migrantes indígenas no han alcanzado una total transformación, y prevalece en ellos gran parte de su cultura tradicional debido a la existencia simultánea de fuerzas centrífugas y centrípetas fuera y dentro de la estructura del grupo. Las primeras, tendientes a desintegrarlo como cultura; y las segundas, tendientes a conservarlo. De este proceso dual, surge la adaptación funcional de la cultura subordinada con el modo de producción capitalista; adaptación que beneficia en primera instancia a este último, y no necesariamente al grupo.

Esta investigación se llevó a cabo a solicitud del Instituto Nacional Indigenista con el objeto de encontrar, en sus resultados, elementos que orientaran su acción entre la población migrante; por esa razón, hacia el final del trabajo se realizan una serie de consideraciones en las que se cuestiona el trabajo asistencialista de instituciones tales como el propio Instituto $\mathrm{Na}$ cional Indigenista (INI), así como también el trabajo organizativo de tipo corporativo desarrollado por sindicatos oficiales e independientes indistintamente, para pasar a proponer una estrategia de trabajo organizativoasistencial, que combine el trabajo asistencial con el trabajo organizativo.

Por último, es necesario aclarar que se realizó trabajo de campo en la zona receptora durante seis meses aproximadamente. Durante este tiempo el proyecto de investigación formaba parte del programa integral de apoyo a la población migrante, a través del cual el INI llevaba a cabo acciones en materia de salud y abasto. Esta particularidad del trabajo de campo permitió establecer una mutua retroalimentación entre la investigación y el trabajo asistencial. Este último se llevó a cabo a través de comités de

2 El artículo 64 establece que las horas de reposo o comida debe ser computado como tiempo efectivo de trabajo en los casos cuando el trabajador no pueda salir de su centro de trabajo; el artículo 69 dice que por cada 6 días de trabajo, el trabajador debe gozar uno de descanso con salario íntegro; el artículo 77 por su parte, otorga el derechode los trabajadores temporales de gozar de una determinada cantidad de días de vacaciones, proporcional al tiempo trabajado; el artículo 80 establece el derecho de los trabajadores a una prima vacacional; el derecho a un aguinaldo anual es otorgado por el artículo 87, y el artículo 117 impone a los patrones el reparto de utilidades entre sus trabajadores. 
salud y abasto organizados en ocho campamentos en el valle de San Quintín; comités que eran conformados por indígenas jornaleros de distinto origen étnico, que tenían como tarea inicial la elaboración de diagnósticos de los lugares donde se hallaban alojados; los resultados de éstos, permitieron establecer las líneas que debíamos seguir en el diagnóstico socioeconómico que posteriormente se realizó a través de la técnica del muestreo. Estos mismos comités nos sirvieron de introductores a los campamentos para la aplicación de cuestionarios, algunos de los miembros de los mismos comités fungieron como informantes clave y, a su vez, ellos nos condujeron a detectar a otros informantes, y finalmente los resultados fueron compartidos y discutidos en asambleas generales de los mismos comités. Por estas características del trabajo de campo, el informe es resultado de una investigación-acción, en la cual la propia población estudiada actuó como parte del equipo de investigación. Las técnicas que se utilizaron fueron: la de observación directa, para contabilizar los cuartos-vivienda de los 20 campamentos existentes en el valle, para establecer las características de la vivienda, y para conocer las condiciones de higiene de estos asentamientos; y la de muestreo al azar, en la aplicación de un cuestionario para encuestar al 27\% de 6,666 familias de jornaleros estacionales de origen étnico diverso, es decir, se encuestaron a 1,800 familias. La aplicación de este cuestionario se llevó a cabo en todos los campamentos del valle y su objetivo era establecer el perfil del migrante y sus niveles mínimos de bienestar. La entrevista con especialistas permitió precisar la información en lo referente a salud y trabajo, en tanto que las realizadas con jornaleros indígenas, fueron llevadas a cabo exclusivamente con mixtecos, ya que esta técnica, además de permitir reafirmar la información obtenida en todos los rubros, se empleó fundamentalmente para reconocer la historia migratoria y algunas características de la cultura, específicamente de dicho grupo oaxaqueño.

El trabajo aquí presentado es sólo un estudio preliminar sobre migrantes temporales; sin embargo, el volumen de la población indígena con residencia permanente en la región es igualmente importante, y queda por hacer un estudio sobre este sector.

\section{ORÍGENES DEL FENÓMENO}

Lo que producía la tierra era caña, frijol, maíz y chile, pero todo era para puro gasto [autoconsumo]; o si la cosecha salía buena, se vendía la mitad. Ultimamente no se quiere dar ya nada porque las tierras se están venciendo y como por allá no se acostumbra a usar el fertilizante, sino que con el mismo abono de la tierra se trabaja, pus ya poco se da. Ora que también falta dinero, porque aunque hay ríos, los terrenos no son planos como los de acá (allá son puros terrenos lomerados, 
quebrados de plano, barrancos y montes), no podemos comprar las bombas necesarias para subir el agua a donde haga falta. $\mathrm{Y}$ es que como le digo, allá no se ven lomas descubiertas como acá, sino puros montes que tiene uno que tumbar y quemar dos meses antes de la siembra (Bonifacio Núñez;información personal:1987).

Quienes componen el flujo migratorio en San Quintín son principalmente los mixtecos, cuyo hábitat, la Mixteca oaxaqueña, es una región montañosa situada al noroeste del estado de Oaxaca, cerca de los estados de Guerrero y Puebla, y dividida en tres subregiones: Mixteca de la Costa, Mixteca Alta y Mixteca Baja (ver figura 1).

En la parte que actualmente habitan los indígenas en esa área, según un diagnóstico preliminar de 1987 realizado por el INI, el $40 \%$ de los suelos agrícolas posee una pedregosidad con dureza de media a fuerte, y el $60 \%$ tiene una pedregosidad media; las pendientes predominantes van del $25 \%$ en adelante y las partes planas representan apenas el $15 \%$ del total de las tierras de cultivo; según ese mismo documento, en la misma región cada agricultor tiene en promedio de 1 a 1.5 hectáreas para uso agrícola. Esto explica el por qué la región mixteca presenta los grados más altos de expulsión de migrantes en todo el país.

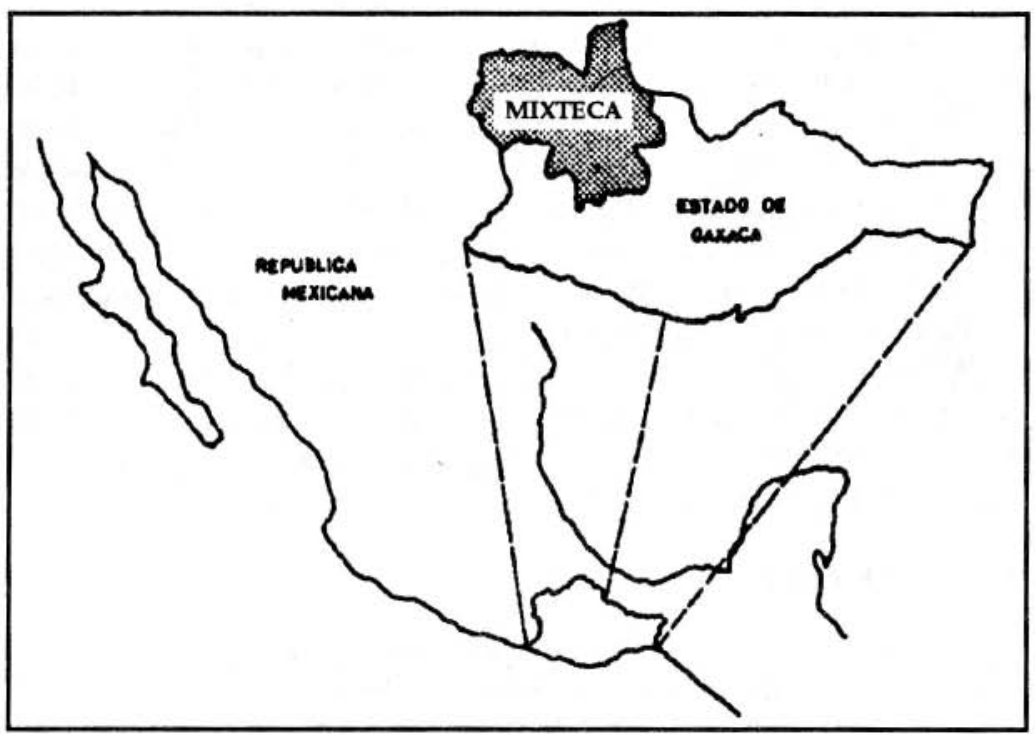

FIGURA 1. Localización de la Mixteca, Oaxaca.

FUENTE: Nolasco Margarita (1985). Aspecto social de la migración en México. SEP-INAH. 
En 1522, los españoles ocuparon el territorio mixteco sembrándolo de enfermedades y violencia, razón por la cual, los indígenas vieron mermada su población en un 50 ó 75\%.(Ravicz, 1965). Así, por miedo a la muerte, abandonaron sus tradicionales áreas de desarrollo en donde disfrutaban de la mejor tierra y se remontaron a los lugares más inaccesibles y estériles de la sierra. Desde entonces, los mixtecos tuvieron que emigrar para sobrevivir.

En 400 años de subordinación, estos indígenas continuaron emigrando hacia distintos puntos de México y del extranjero; en las últimas tres décadas los recibió Guerrero, Veracruz, Sinaloa y actualmente Baja California.

En Baja California la agricultura se ha caracterizado siempre por su desarrollo y modernización, determinados por su vecindad con los Estados Unidos y por tener importantes extensiones de tierra bajo el régimen de riego.Esto ha definido, por una parte, la alta rentabilidad de la agricultura del estado, orientada fundamentalmente hacia la exportación, y por otra su elevada demanda de fuerza de trabajo.

Desde el surgimiento de la actividad agrícola a principios de este siglo, Baja California figuró, nacional e internacionalmente, como un polo de atracción de flujos migratorios provenientes de zonas con economías deprimidas y regímenes agrícolas de temporal. Antes de que el valle de San Quintín fuera descubierto como un lugar propicio para la horticultura, el valle de Mexicali recibió los primeros contingentes de migrantes procedentes de Michoacán, Guanajuato, Jalisco, Zacatecas y Nayarit, para satisfacer sus necesidades de fuerza de trabajo en pleno auge algodonero. Sin embargo, al finalizar la década de los cincuentas, el mercado para el algodón entró en crisis como resultado de la incorporación de nuevos países a la producción de la fibra natural, y por el descubrimiento de productos sintéticos que la sustituían. Esto obligó a los productores a restringir el área algodonera y a buscar cultivos alternativos de exportación. Fue entonces cuando se encontró en la región de San Quintín agua disponible y el clima propicio para producir hortaliza en el verano, durante los meses en los que Estados Unidos - principal consumidor - no puede producirla. Por ello, mientras que en San Quintín la horticultura ocupa cerca de 5,500 hectáreas, en el valle de Mexicali no rebasa las 1,000 (SARH, 1986).

La contracción de la superficie algodonera y la tecnificación de su producción disminuyeron la demanda de mano de obra en el valle de Mexicali, al tiempo que las hortalizas en la zona costera fueron cobrando importancia. Por otra parte, debido a que en el valle de Mexicali la agricultura se diversificó en varios cultivos, los trabajadores agrícolas pudieron establecerse definitivamente en este lugar para satisfacer las necesidades de fuerza de trabajo todo el año; no así en el valle de San Quintín, en donde el carácter estacional de la horticultura, requirió de 
jornaleros temporales sólo por seis meses al año. Esto explica el por qué los indígenas semicampesinos (que complementan sus ingresos de asalariados con lo que producen en sus parcelas de su lugar de origen) establecieron como destino principalmente la zona costa; y no el valle de Mexicali.

Hasta hoy, la década de los ochenta ha sido la más importante para los productores hortícolas de Baja California, ya que en estos últimos años, desde el punto de vista de la extensión, el trigo ha ocupado el primer lugar, el algodón el segundo y la hortaliza el tercero. Desde el punto de vista del valor de la producción, el algodón ocupa el primer lugar con el 32\% del valor total de la producción agrícola, las hortalizas el segundo con el $22 \%$, y el trigo el tercero con el $14 \%$; y atendiendo al rendimiento, resultado de la relación entre el valor de la producción y la superficie destinada a la misma, tenemos que la hortaliza tiene el primer lugar participando con ese $22 \%$, ocupando tan solo el $5 \%$ de la superficie cultivada, debido a que el rendimiento de la horticultura en Baja California, de 35.5 ton/ha., equivale al doble del rendimiento promedio nacional, que es de 17.5 ton/ha.(SARH,1986).

Es importante hacer notar que a pesar de la modernización de la agricultura, principalmente en el terreno de las hortalizas, la mecanización de este cultivo sólo se ha dado, hasta el momento, en el proceso de empaque y selección, por lo que los productores han tenido que buscar en el mercado laboral un volumen importante de trabajadores para el ciclo vegetativo; trabajadores provenientes fundamentalmente de la Mixteca Baja de Oaxaca que, desde 1959, los empresarios horticultores de Baja California encontraron en la región de Sinaloa debido a que habían sido contratados para labores similares nueve años antes. Al contratarlos, el estado de Baja California pasó a constituir un eslabón en la ruta migratoria más importante de México, la del noroeste, compuesta por los estados de Nayarit, Sinaloa, Sonora, Baja California y Baja California Sur.

Esta ruta, por las características estacionales de sus cultivos permite en la actualidad la circulación constante del $62 \%$ de la mano de obra migrante de todo el país (INEA, 1986).

Así, con el desarrollo de la horticultura en Baja California no sólo hubo un cambio en el cultivo que por excelencia venía demandando grandes volúmenes de fuerza de trabajo migrante, sino un cambio en el polo regional con mayor concentración de jornaleros estacionales, mientras en el valle de Mexicali la alternancia de la horticultura con el algodonero y los forrajes estableció una demanda más estable de mano de obra, permitiendo el asentamiento definitivo de trabajadores agrícolas. En la costa, en los valles del municipio de Ensenada, particularmente en el valle de San Quintín, se registró en los últimos años un notable crecimiento de la 
producción de hortalizas, ${ }^{3}$ dentro de las cuales el tomate de vara empezó a ocupar un lugar importante, tanto por su superficie ocupada (aproximadamente el $57.4 \%$ ) como por la captación de mano de obra que empezó a demandar para su recolección( $83.4 \%$ del total de jornales); pero esto únicamente en los meses de mayo a agosto.

En el ciclo 1984-1985, Baja California exportó 68,268 toneladas de hortaliza, que según la SARH representaron el 30\% del total de la producción hortícola en San Quintín (227,560 toneladas); para ello, en esta última emplearon 5,689 hectáreas de las 10,000 de riego disponibles en el lugar, y cerca de 30,000 jornaleros indígenas estacionales.

Hay que destacar que los productores obstruyen toda cuantificación de sus trabajadores, porque al ocultar el volumen total de jornaleros quedan exentos de ciertas obligaciones laborales, así como también impiden que se estime la superficie que cultivan para ocultar que explotan una cantidad de agua superior a la permitida oficialmente: 42 millones de milímetros cúbicos, cuando sólo existe una recarga de 20 millones, lo que representa una sobreexplotación de 22 millones de milímetros cúbicos ( La Voz de la Frontera, 20 de enero de 1988).

De acuerdo con la clasificación del Centro de Estudios para América Latina (CEPAL) que divide a los productores del campo en unidades campesinas, empresariales y transicionales, Baja California aparece a nivel nacional como ejemplo de casos extremos por su elevado porcentaje de unidades productivas empresariales y baja proporción de unidades campesinas; pues mientras que a nivel nacional el sector de empresas capitalistas no pasa del $1.8 \%$ del total de las unidades, en siete de las entidades, entre ellas Baja California, pasa del 5\% (Bendesky, 1986).

Sin embargo, esto puede ser sólo un espejismo creado por las formas de asociación adoptadas entre ejidatarios y pequeños propietarios. A los primeros, sin capital ni posibilidades de obtenerlo, les resulta más atractivo otorgar la tierra en renta clandestina que arriesgar una inversión propia haciéndola producir; mientras que los segundos, con la expectativa de convertirse en empresarios agrícolas, ponen su atención en la agroexportación, para lo cual requieren de altos rendimientos y bajos riesgos en su producción, que mediante el empleo de una moderna y costosa tecnología; requieren además, del arrendamiento de grandes extensiones de tierra que pueden obtener únicamente de pequeños propictarios más débiles cconómicamente

3 De 1977 a 1985 el incremento de la superficie hortícola de riego tuvo una tasa de crecimiento anual del 15.4\%; de estos nueve años, los últimos cuatro (82-85) obtuvieron más allá de la media anual, alcanzando una tasa del 19\%, SARH, Distrito de Riego Núm.14, Subjefatura de Distrito de Operación y Desarrollo. 
o de ejidatarios, a través de una disponibilidad inmediata de dinero; por otra parte, necesitan seguridad en el mercado exterior y por último, de fuerza de trabajo dócil y en grandes volúmenes para ocuparla sólo periódicamente.

Así es como la agricultura por contrato, que es la principal forma en que las empresas transnacionales se relacionan con los medianos y grandes productores privados, permite la disponibilidad inmediata de recursos para el arrendamiento de tierra, la introducción de paquetes tecnológicos que comprenden la asesoría técnica, sistemas de riego por goteo, polinización artificial, semillas y productos químicos importados, y sobre todo la seguridad del mercado que ofrecen estas compañías en el exterior donde se concretiza una ganancia extraordinaria que resulta de la diferencia del pago de salarios en pesos y la venta del producto en dólares; ganancia que además va incrementándose con la paulatina devaluación de nuestra moneda.

Los productores nacionales que trabajan mediante la agricultura por contrato en el valle de San Quintín son alrededor de diez, destacando la Empresa Canelos A, B, C (ver figura 2).

Las empresas transnacionales que operan ahí son las mismas que operaron en los sesenta en Sinaloa; $y$ antes como ahora han buscado altas tasas de ganancia a través de la sobreexplotación de los recursos naturales, (que en el caso de San Quintín se trata de mantos acuíferos que se explotan al doble de su capacidad de recarga anual) y de la sobreexplotación de la mano de obra principalmente de origen mixteco, que por su bajo precio y docilidad han permitido sostener el moderno tinglado de la producción agrícola, haciendo posible a los ejidatarios recibir ingresos por el arrendamiento de sus parcelas; a los medianos y grandes productores obtener jugosas ganancias en dólares y a las empresas transnacionales apropiarse de parte del excedente generado con el control del mercado internacional e incluso parte del mercado nacional. Todo ello a expensas de la sobrexplotación de los jornaleros indígenas que sufren de condiciones de vida y de trabajo infrahumanas.

\section{CONDICIONES DE VIDA Y DE TRABAJO}

Independientemente de la etnia a la que pertenezcan (mixtecos,zapotecos, triquis, etc.), las condiciones de vida y de trabajo de todos los migrantes indígenas en San Quintín son más desventajosas que las de los migrantes mestizos, pues por su condición étnica son discriminados por los productores y por la población en general. A los indígenas por ejemplo, se les asignan los trabajos más pesados en el campo, mientras que a los no indígenas que acuden también periódicamente a San Quintín, se les ubica en el empaque. Los productores justifican esta situación diciendo que los indios no tienen la 
estatura necesaria para alcanzar la banda de selección del empaque, por lo que en este trabajo sólo se contratan a no indígenas. Si este argumento fuera cierto, los productores no tendrían necesidad de establecer una sistemática selección del trabajador en base a su origen étnico para asignar un puesto en el empaque; la posibilidad de aspirar a este trabajo, que resulta menos pesado que el del campo, debería existir en general para todos los trabajadores independientemente de su origen étnico, pues igual encontramos en el campo indígenas de estatura alta, como empacadores muy bajos que utilizan tarimas de madera para alcanzar dicha banda. Si la justificación de los patrones fuera correcta, entonces el criterio para contratar empleados en el empaque, debería ser la estatura no la etnia.

Por otra parte, los indígenas son acomodados en campamentos insalubres de lámina con piso de tierra y sin servicio alguno y los mestizos en viviendas construidas de concreto, equipadas con estufas de gas y canchas de baloncesto. En este caso la justificación de los productores es menos sutil: "son indios y así están acostumbrados a vivir" (Don Benjamín Rodríguez, productor de San Quintín; información personal).

A San Quintín acuden de mayo a septiembre cerca de 30 mil jornaleros estacionales a levantar la hortaliza; sin embargo, es común escuchar entre los habitantes con más años en ese lugar, que el volumen de migrantes en otros años ha sido de 50 a 80 mil trabajadores.

En cuanto a la composición por sexo y edad de este contingente heterogéneo de indígenas, tenemos que el $52 \%$ tiene de 15 a 22 años de edad y el $72 \%$ es del sexo masculino; y atendiendo a su composición étnica, el $63 \%$ es de origen mixteco, siguiéndole en importancia los zapotecos, los triquis, los nahuas y los tarascos. Esto hace del grupo mixteco, el grupo étnico numéricamente más importante en el estado de Baja California.

La duración del migrante en la zona receptora puede ser corta (de dos a tres meses), media (de cuatro a seis meses), y prolongada (de siete meses o más). El volumen principal de los migrantes se ubica en el segundo grupo y le sigue en importancia el tercero, pues el $35 \%$ posee una tendencia a establecerse.

De acuerdo a su ruta, están aquéllos que retornan a su pueblo (más del $50 \%)$; los que tienen la expectativa de quedarse (35\%); y los que se encuentran migrando permanentemente en círculo (el 12\%).

El $31 \%$ tiene de uno a cuatro años migrando; el $27 \%$ de 9 a 24 años, y el $22 \%$ de uno a seis meses. De todos ellos, el $53 \%$ tiene menos de cuatro años acudiendo a San Quintín.

En nuestra encuesta el 100\% manifestó como causa de su migración la faita de empleo y la mala calidad de la tierra en sus pueblos; y a pesar de que el $30 \%$ tiene parcelas allá, el $31 \%$ al regresar a su lugar de origen sigue siendo asalariado. 


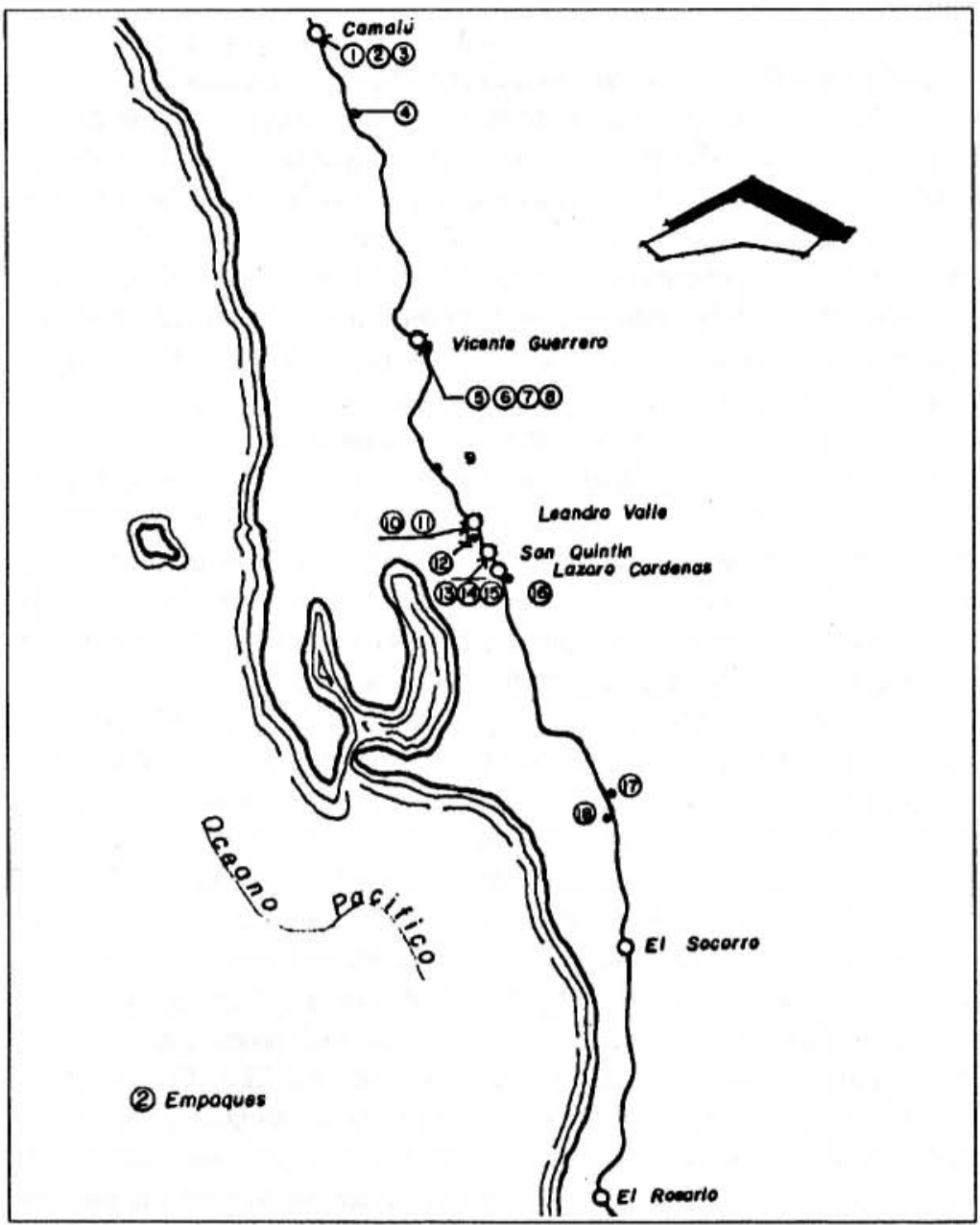

\section{FIGURA 2. Localización de empaques en San Quintín, B.C.}

FUENTE: Everardo Garduño, et al. 1987. Proyecto "Mixtecos en Baja California. El caso de San Quintín", UABC.

\section{Empaque}

1. Empaque García

2. Hermanos García

3. Emp. de la unión

4. Emp. de la entrada al aguaje

5. Emp. dos amigos

6. Emp. de hortalizas

7. Empaque Terry

8. Emp. la bolita

9. Empaque ABC
Propietario

Hermanos García

Hermanos García

U. de Ejidatarios

Castañeda

Librado Heredia

González

Hermanos García

Liberato Romo

Canelos

\section{Empaque}

10. Empaque Magaña

11. Emp. de M. García

12. Emp. Califomia

13. La Campana

14. Emp. Valladolid

15. E. Nuevo de Rodríguez

16. Emp. de Pedro Soto

17. Emp. de la Unión

de Ejidatarios

18. Empaque Los Pinos
Propietario

Magaña

Miguel García

Librado Heredia Manuel Castañeda

Antonio Valladolid

Hnos. Rodríguez

Pedro Soto

Unión de Ejidatarios

Hnos. Rodríguez 
Son 23 los asentamientos más importantes en el valle, en los que se encuentra dispersa la población indígena migrante (ver figura 3).

De este número, seis corresponden a poblados propiamente dichos, con 461 cuartos-vivienda, donde 1,844 migrantes, aproximadamente, se han asentado de manera definitiva y tienen acceso a servicios como la electricidad, educación y abasto; los 17 restantes son campamentos improvisados por el productor sin ningún tipo de servicio. En 14 de los campamentos que fueron visitados se contabilizaron 1,894 cuartos-vivienda, es decir, el $80 \%$ de la vivienda contabilizada, donde habitan, en la temporada de menor afluencia de jornaleros, 7,576 persona (ver cuadro 1).

Uno de estos campamentos está compuesto por largas galeras de lámina que se extienden en la parte menos propicia para el cultivo; se trata de enormes cajones rectangulares divididos en cuartos de 16 metros cuadrados. En estos lugares no hay letrinas, o donde las hay, son tan pequeñas e incómodas que no se usan. En 14 campamentos hay sólo 148 letrinas, lo que calculando un promedio de 4 personas por cuarto en la temporada de menor afluencia a San Quintín (7,576 jornaleros) nos da un promedio de 51 usuarios por letrina. En el campamento denominado El aguaje del burro, hay una letrina para 192 usuarios y en los campos Diez, Santa Lucía y El Pabellón, donde se concentran 116, 400 y 128 trabajadores respectivamente, no hay ninguna (ver cuadro 1 ).

Los baños son apenas cuatro varas clavadas en el suelo cubiertas con plástico. El promedio de usuarios por baño es el mismo que en el caso de las letrinas, 51 por cada baño (ver cuadro 1 ).

Ningún campamento cuenta con electricidad y el agua se obtiene de aguajes y depósitos sumamente contaminados (ver cuadro 2).

Las tolvaneras en el campamento durante el verano, $y$ en el invierno las lluvias, son cosa de todos los días; fenómenos ante los cuales la vivienda no tiene ninguna protección: los cuartos se gotean abundantemente y en su piso de tierra se forman lodasales. En verano, la lámina de las paredes es en exceso caliente y en invierno es sumamente fría. Todo esto propicia la proliferación de enfermedades relacionadas con la falta de higiene y las condiciones sanitarias del lugar.

En el cuadro de morbilidad establecido por el programa de unidades médicas móviles del INI, las enfermedades respiratorias, resultado de los cambios bruscos de clima y la mala condición de la vivienda, ocupan el primer lugar en frecuencia con el $29 \%$. El segundo lugar lo ocupan las enfermedades gastrointestinales, resultado de la falta de higiene en los campamentos, con el $28 \%$ de frecuencia. Y el tercer lugar, con el $18 \%$, las enfermedades reumáticas que resultan de las variaciones del clima y las jornadas extenuantes de trabajo. 


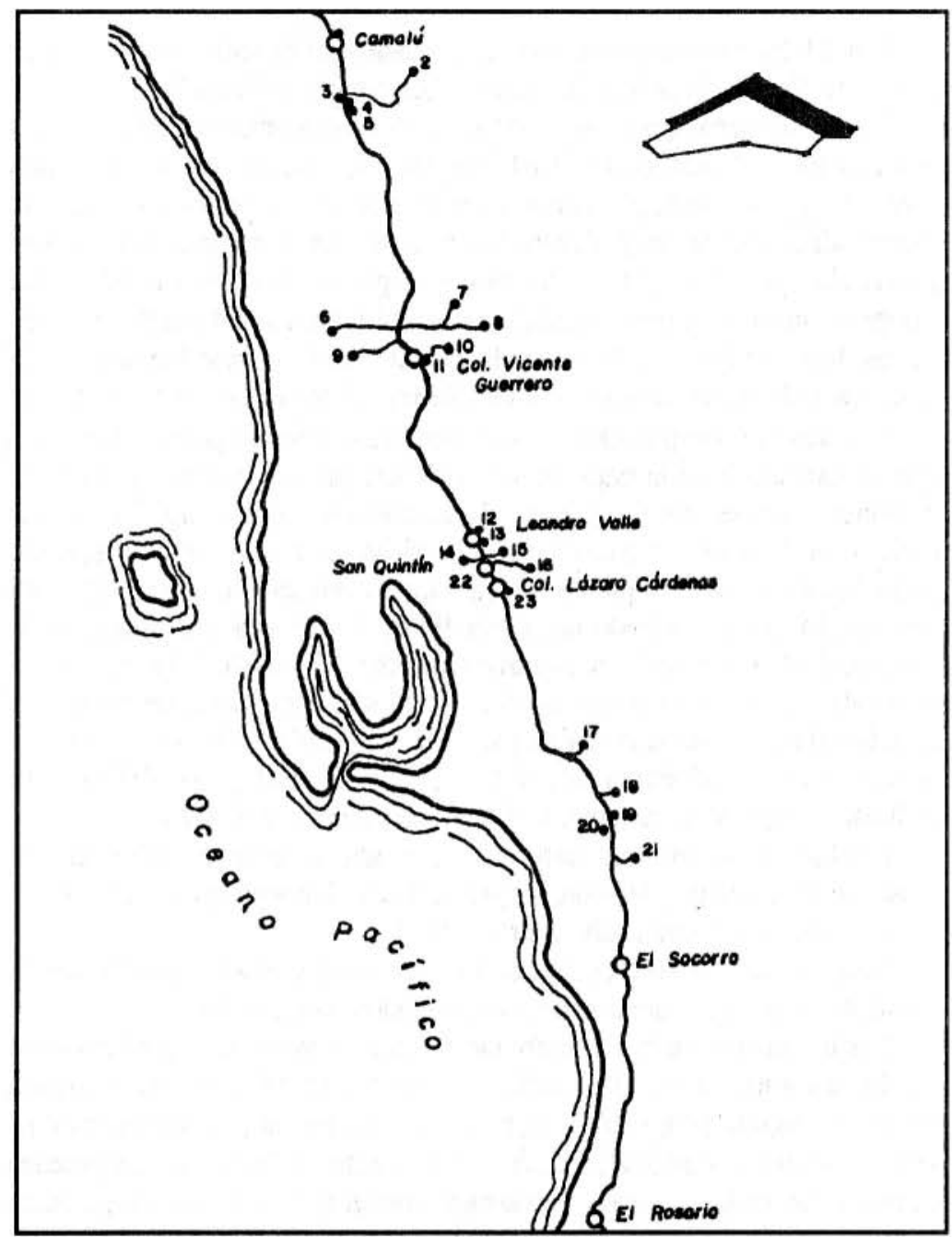

FIGURA 3. Localización de campamentos en San Quintín, B.C.

FUENTE: Everardo Garduño, et al. 1987. Proyecto "Mixtecos en Baja California. El caso de San Quintín", UABC.

Campamentos: 1 . Camalú

2. Aguaje del burro

3. San Ângel

4. Santa Cruz

5. Colonia Militar

6. Del Mar

7. Llamas

8. Santa Lucía
9. Santa Rosa

10. Aragón

11.Colonia Guerrero

12. EME

13. El Milagro

14. Las Cebollas

15. Las Escobas

16. Walter
17. San Simón

18. Campo 10

19. Campo 1

20. Las Pulgas

21. El Pabellón

22. San Quintín

23. Colonia Lázaro Cárdenas 
CUADRO 1. Condiciones de las viviendas en los campamentos.

\begin{tabular}{|c|c|c|c|c|c|c|c|}
\hline \multirow[t]{2}{*}{ Campo } & \multirow{2}{*}{$\begin{array}{l}\text { No. de } \\
\text { viviendas }\end{array}$} & \multicolumn{4}{|c|}{ Tipo de material de construcción } & \multirow{2}{*}{$\begin{array}{l}\text { No. de } \\
\text { Letrinas }\end{array}$} & \multirow{2}{*}{$\begin{array}{l}\text { No. de } \\
\text { Baños }\end{array}$} \\
\hline & & Lámina & Madera & Concreto & Plástico & & \\
\hline Aguaje Burro* & 96 & 0 & 0 & 86 & 10 & 2 & 19 \\
\hline Del Mar & 340 & 340 & 0 & 0 & 0 & 41 & 30 \\
\hline Llamas & 70 & 32 & 38 & 0 & 0 & 4 & 11 \\
\hline Aragón & 73 & 33 & & & 40 & & \\
\hline Walter & 200 & 200 & 0 & 0 & 0 & 20 & 26 \\
\hline San Simón & 490 & 490 & 0 & 0 & 0 & 42 & 59 \\
\hline Las Pulgas & 260 & 260 & 0 & 0 & 0 & 10 & 52 \\
\hline Campo 10 & 29 & 29 & 0 & 0 & 0 & 0 & 4 \\
\hline Santa Rosa & 62 & 56 & 3 & 3 & 0 & 14 & 40 \\
\hline Santa Lucía & 100 & 0 & 87 & 13 & 0 & 0 & 8 \\
\hline Las Cebollas & 51 & 0 & 26 & 1 & 24 & 6 & 9 \\
\hline Las Escobas & 44 & 44 & 0 & 0 & 0 & 5 & 3 \\
\hline Campo 1 & 47 & 0 & 0 & 41 & 0 & 4 & 16 \\
\hline El Pabellón & 32 & 26 & 2 & 0 & 4 & 0 & 4 \\
\hline Totales & 1894 & 1510 & 156 & 144 & 78 & 148 & 281 \\
\hline
\end{tabular}

FUENTE: Proyecto: "Mixtccos en Baja California. El caso de San Quintín". 1987. UABC. Serie: Musco.

Sin embargo, si atendemos a las causas, más que al tipo de enfermedad, tenemos que este mismo programa de unidades médicas móviles, establece precisamente a las condiciones insalubres como la principal causa de enfermedad y muerte entre la población migrante, pues al $28 \%$ de enfermedades gastrointestinales le debemos sumar la helmintiasis (parásitos) y las enfermedades de la piel, alcanzando el $43 \%$ de enfermedades y $46 \%$ de muertes ocasionadas por la insalubridad en que los productores alojan a sus trabajadores. En segundo lugar, se mantendrían las enfermedades respiratorias; y en tercero, las reumáticas. Y si bien de toda la población que se accrca a la consulta médica, sólo el $10 \%$ lo hace por malestares ocasionados por su deficiente alimentación, en el $27 \%$ de las muertes registradas, a pesar de que la causa del deceso haya sido otra, la desnutrición o la anemia han sido decisivas para tal desenlace. Además, de acuerdo a los registros de muerte de la Agencia del Ministerio Público, de cada diez casos, siete son niños menores de dos años. 
CUADRO 2. Necesidades prioritarias por campamento.

\begin{tabular}{|c|c|c|c|c|c|c|c|c|c|c|c|c|c|c|c|}
\hline \multirow[t]{2}{*}{ CAMPO } & \multicolumn{6}{|c|}{ Vivienda y servicios } & \multirow{2}{*}{$\begin{array}{c}\text { Abasto } \\
\begin{array}{c}\text { Prog. de } \\
\text { abasto }\end{array}\end{array}$} & \multicolumn{4}{|c|}{ Educación } & \multicolumn{3}{|c|}{ Salud } & \multirow{2}{*}{$\begin{array}{l}\text { Recrea- } \\
\text { ción }\end{array}$} \\
\hline & $\begin{array}{l}\text { Viv. } \\
\text { Const. }\end{array}$ & Mejor & $\begin{array}{l}\text { Introduc. } \\
\text { agua pot. } \\
\text { y red. }\end{array}$ & $\begin{array}{l}\text { Letrinas } \\
\text { Const. }\end{array}$ & Mant. & $\begin{array}{l}\text { Electrif. } \\
\text { distanc. }\end{array}$ & & \multicolumn{2}{|c|}{$\begin{array}{c}\text { Aulas } \\
\text { Cons. Habi. }\end{array}$} & $\begin{array}{l}\text { Asignac. } \\
\text { Pers. Doc. }\end{array}$ & $\begin{array}{c}\text { Promotor } \\
\text { INEA }\end{array}$ & $\begin{array}{l}\text { Atenc. } \\
\text { médica }\end{array}$ & $\begin{array}{l}\text { Control } \\
\text { fauna } \\
\text { nociva }\end{array}$ & $\begin{array}{c}\text { Recolec } \\
\text { basura }\end{array}$ & \\
\hline Aguaje & $x$ & & $x$ & $x$ & & $\times 8 \mathrm{~km}$ & & & & & & $x$ & $\mathrm{x}$ & $x$ & $x$ \\
\hline Del Mar & $x$ & & & & & $\times 2 \mathrm{~km}$ & $x$ & $x$ & $x$ & $x$ & & & $x$ & & $x$ \\
\hline Llamas & $x$ & $x$ & & & & $x 1 \mathrm{~km}$ & & $x$ & $x$ & & & $x$ & $x$ & $x$ & $x$ \\
\hline Aragón & $x$ & & $x$ & & & $x 1 \mathrm{~km}$ & & $x$ & $x$ & & & $x$ & $x$ & $x$ & $x$ \\
\hline Walter & & & & & & x $1 \mathrm{~km}$ & $x$ & $x$ & $x$ & $x$ & & & $\mathrm{x}$ & & $x$ \\
\hline San Sim & & & & & $x$ & x $1 \mathrm{~km}$ & $x$ & $x$ & $x$ & & & & $x$ & & $x$ \\
\hline Las Pulg & gas & & & & & x $0 \mathrm{~km}$. & & & & & & $\mathrm{x}$ & $x$ & & $\mathrm{x}$ \\
\hline Campo 1 & 10 & & $x$ & $x$ & & x $1 \mathrm{~km}$ & & $\mathrm{x}$ & $x$ & & $x$ & $x$ & $x$ & $x$ & $x$ \\
\hline Sta. Rose & & $\mathrm{x}$ & $\mathrm{x}$ & & & x $0 \mathrm{~km}$ & & $x$ & $x$ & & $\mathrm{x}$ & $x$ & $x$ & & $\mathrm{x}$ \\
\hline Sta. Lucí & sía & $x$ & $\mathrm{x}$ & $x$ & & x $0 \mathrm{~km}$ & & $x$ & $\mathrm{x}$ & & & $x$ & $x$ & & $\mathrm{x}$ \\
\hline Las Cebo & ollas & & Reubicación & & & & & & & & & & $\mathrm{x}$ & $\mathrm{x}$ & $x$ \\
\hline Las Esco & obas & & & $\mathrm{x}$ & & x $3 \mathrm{~km}$ & . & $\mathrm{x}$ & $x$ & & $x$ & $x$ & $x$ & & $\mathrm{x}$ \\
\hline Campo 1 & & $x$ & $\mathbf{x}$ & $x$ & & x $1.5 \mathrm{~km}$ & & & & & & & $\mathrm{x}$ & $\mathbf{x}$ & $\mathbf{x}$ \\
\hline El Pabell & llón & $x$ & & $\mathrm{x}$ & & $\mathrm{x} 2 \mathrm{~km}$ & & $x$ & $\mathrm{x}$ & $x$ & $\mathrm{x}$ & $\mathrm{x}$ & $x$ & $\mathrm{x}$ & $\mathrm{x}$ \\
\hline Alb. los & Pinos & & & $\mathrm{x}$ & & x $0 \mathrm{~km}$ & & & $\mathbf{x}$ & & & & $\mathrm{x}$ & & $x$ \\
\hline Alb. 29 & & & $x$ & & & x $0 \mathrm{~km}$ & & $\mathrm{x}$ & & & & & $x$ & & $\mathrm{x}$ \\
\hline
\end{tabular}

FUENTE: Proyecto "Mixtecos en Baja California. El caso de San Quintín." UABC. 
En cuanto a las condiciones de trabajo tenemos que los indígenas son considerados trabajadores estacionales por quienes los contratan, pese a que muchos de ellos tienen más de 10 años trabajando para una misma empresa. Debido a este carácter eventual al que son sujetos, no se les hacen efectivos los derechos más elementales de la Ley Federal del Trabajo, como son los considerados en los artículos 64 (referente a la contabilización de la hora de comida como hora de trabajo cuando el trabajador no puede ir a su casa a comer), 69 (relativo al pago del séptimo día), 77 (derecho a vacaciones), 80 (derecho a prima vacacional), 87 (pago de aguinaldo), 117 (pago de utilidades), ni los artículos comprendidos entre el 279 al 284 (sobre los derechos en general de los trabajadores del campo). Incluso, para el caso de las horas extras en algunos ranchos son obligatorias, no voluntarias, y las mujeres embarazadas no gozan de consideración alguna, ni aun de sus 45 días antes y después del parto.

Pese a esto, no hay organización sindical que defienda a los jornaleros indígenas y los oriente, aunque todos pagan cuota a algún sindicato del estado. Los intentos que ha habido para organizarlos en forma independiente no han sido reconocidos aún por el gobiemo, sino por el contrario han sido reprimidos.

\section{EL PROCESO DE ACULTURACIÓN}

Como ya se ha dicho anteriormente, los indígenas migrantes, independientemente de su origen étnico, constituyen una misma clase social al estar ubicados en el mismo sitio dentro del proceso productivo y al compartir las mismas condiciones de vida y de trabajo. Sin embargo, precisamente por su origen étnico es importante atender a su cultura concebida como una estrategia de supervivencia y reproducción de la etnia. Para esto, en el análisis del proceso de aculturación, nos hemos centrado en el grupo étnico que conforma el volumen principal del contingente migratorio: el grupo mixteco.

Desde el punto de vista de su cultura, los mixtecos iniciaron su transformación con el contacto europeo, y ésta ha continuado hasta nuestros días, ya sea en sus comunidades de origen, o en el ámbito de su vida cotidiana en los campamentos de la zona receptora de la migración. Sin embargo, su situación de migrantes ha colocado a estos indígenas en una nueva fase que acelera su proceso de aculturación, que se da fundamentalmente mediante la imposición de pautas y normas culturales ajenas al grupo: "cultura impuesta" (Bonfil,1982); o bien, mediante el despojo de elementos tradicionales de su cultura que para la cultura dominante resultan disfuncionales: "cultura enajenada" (Bonfil, 1982). En 
ambos casos, los cambios se suscitan en una dinámica tal que rebasan la capacidad de respuesta o apropiación del grupo, ocasionándole trastornos y desequilibrios en su modo tradicional de vida.

En su lugar de origen, las casas suelen estar dispersas y ser rectangulares o redondas, con una sola entrada y paredes de adobe, carrizo o acacia embadurnada. Los techos son de paja y cuelgan hasta la altura de la cabeza; Como las viviendas no tienen ventana, existe un espacio entre el techo y la pared que permite la salida de humo del fogón.

A diferencia de esto, en San Quintín lo primero que salta a la vista es el patrón de asentamiento concentrado, en donde es común que los productores impongan el hacinamiento. Se trata de campamentos conformados por hileras de cuartos de lámina seccionadas en habitaciones cuadradas de $16 \mathrm{~m}^{2}$.

Esta forma de concentrar a indígenas originarios de distintos pueblos e incluso de distinta etnia en reducidos espacios, potencializa los conflictos interétnicos que traen consigo, obstaculizando la participación de las personas en los grupos asistenciales y eliminando la posibilidad de reproducir las formas tradicionales de organización como las mayordomías y el tequio ${ }^{4}$, e incluso, da pie a revueltas con trágicos saldos.

Otro aspecto de la vida cotidiana de los mixtecos, alterado por la migración, es la rutina diaria. En su lugar de origen establecen un manejo del tiempo a través del sol, sus horarios no se rigen por horas y minutos, sino por secciones generales del día; mientras que en la zona receptora, en su condición asalariada, la familia tiene que adoptar el manejo del reloj para sistematizar toda su vida en aras de un mejor rendimiento en el trabajo; por otra parte, su alimentación basada en los frijoles con cebolla, tortillas de maíz, salsa, berros, hongos, hierbas y verduras silvestres, café y un poco de carne, es abandonada al incoporar a su alimentación el alimento "rápido", el alimento "chatarra" compuesto por pastas, aceite, golosinas, refrescos, etc.; (Ravicz, 1965). La vestimenta tradicional también deja de emplearse por la presión mestiza, por la necesidad de viajar con un equipaje ligero, o bien, por el tipo de trabajo que les impone la necesidad de un vestuario diferente.

En cuanto a su idioma, existe una transformación parcial o la pérdida completa de la lengua materna; o porque se empiezan a constituir híbridos durante la migración, ya sea porque al ser de distinto origen étnico requieren de una tercer lengua para comunicarse, o simplemente los padres prefieren no enseñar a sus hijos el idioma para que no sufran como ellos sufrieron.

4 Sistema de trabajo colectivo sin la existencia del salario. 
En sus formas tradicionales de curarse también existe una tendencia al olvido absoluto de las plantas medicinales, primero porque en San Quintín no existe la misma variedad de plantas silvestres que en Oaxaca y las condiciones climáticas impiden su cultivo, y segundo, por la presión de la cultura dominante que menosprecia el uso de estas plantas e impone directa o indirectamente el empleo de medicamentos industrializados.

Por último, en lo religioso, los mixtecos en San Quintín se encuentran expuestos ante un sinnúmero de sectas religiosas que han logrado incorporar a sus iglesias contingentes importantes de indígenas. Esta penetración religiosa como es sabido, introduce conflictos entre los migrantes y deteriora su cohesión al deteriorar su identidad étnica.

Pese a todas las anteriores agresiones y desequilibrios que sufre la cultura de los migrantes mixtecos en San Quintín, podemos identificar un proceso de reafirmación de su identidad entre aquellos migrantes que han adquirido cierta estabilidad y residencia en la región.

Dicho proceso, sin embargo, no se da a través de un retorno a la cultura original, sino por una parte, a través de la adaptación de algunos aspectos de ésta a las condiciones de la zona receptora (cultura autónoma), como estrategia para sobrevivir en su nueva condición igualmente mísera de proletarios; y por otra parte, a través de la adopción funcional de elementos de la cultura anfitriona (cultura apropiada) (Bonfil, 1982).

Adaptación y adopción, en eso consiste la reafirmación de la identidad indígena; en cambiar para preservar.

En este sentido, si bien la migración es un mecanismo de incorporación de los indígenas al capitalismo, ante la incapacidad de éste para ofrecerles la proletarización definitiva, ha propiciado que los mixtecos la adopten como estrategia para hacer subsistir su sector tradicional, y por lo tanto, como forma de vida que, en lugar de ser síntoma de descomposición y muerte del grupo, es una vía concreta para la refuncionalización de su economía campesina.

Por otra parte, en San Quintín, Baja California algunos mixtecos han construido espacios de reproducción cultural en donde subsisten rasgos tradicionales de su cultura, adoptando un patrón de asentamiento más voluntario; tal es el caso de los barrios indígenas de la colonia Guerrero, colonia Maclovio Rojas, colonia Flores Magón. Se trata de conglomerados por familia, etnia o pueblo, que disponen del espacio habitacional de una manera más propia y libre. En el caso de la vivienda triqui por ejemplo, es común encontrar en su interior, el telar de cintura, la vestimenta tradicional, y en su exterior, el baño de vapor o temascal.

Es en estos barrios en donde resurgen los cargos de mayordomo, el tequio y el empleo de plantas medicinales. Es allí en donde se hace común el 
mecapal elaborado con ixtle recogido de la pizca del tomate; los tenates con palma traída desde Oaxaca, o bien hechos con plástico, los juguetes de madera, los bordados y los sombreros de plástico, es en estos asentamientos donde se aprecian las cocinas de carrizo que vienen a solucionar el problema del humo en el interior de la vivienda; y es entre estos jornaleros en donde empieza a retomarse la tradición musical y mediante ésta empiezan a expresar sus problemas de proletarios agrícolas en Baja California.

\section{LA INTEGRACIÓN SOCIAL}

Sin embargo, en aquellos sitios en donde tiene lugar la reafirmación de la identidad a través de procesos de adaptación y adopción cultural, el aspecto organizativo no se refuncionaliza de manera importante, haciéndose urgente la presencia de una fuerza organizada que contrarreste la atomización del grupo y la estimulación de los conflictos interétnicos con el fin de recuperar los esquemas tradicionales de participación colectiva y democrática, readecuándolos a la nueva circunstancia de proletarios, e imprimiéndoles una orientación sindical.

Esto nos conduce entonces a reconocer que el fenómeno del contacto no puede ser visto únicamente desde el punto de vista cultural, puesto que implica una problemática también social; incluso, como nos lo dice Gonzálo Aguirre Beltrán, algunos sociólogos y antropólogos consideran que "lo trascendente no es el intercambio o la transferencia de elementos culturales sino las relaciones de interdependencia que se establecen entre los grupos interactuantes que conviven en un mismo territorio" (1957:46), de tal forma que para la perspectiva social, lo importante no es determinar los niveles de aculturación de un grupo en contacto con otro, sino determinar los niveles de integración de ambos. Entendiendo a la integración como un proceso social que tiende a armonizar y unificar diversas unidades antagónicas, ya sean elementos de la personalidad de los individuos, de los grupos, o de mayores agregados sociales (Fairchild,1949:157). Por esto, el proceso de integración se caracteriza por la tendencia a resolver el conflicto entre fuerzas de sistemas opuestos, en un plano de igualdad.

Según este mismo autor, para la perspectiva social las fuerzas en conflicto son:

a) De concentración. Cuando el proceso incorpora dentro de la estructura social del grupo dominante, a los individuos que componen la comunidad con la que dicha estructura entra en contacto.

b) De dispersión. Cuando de manera contraria, el proceso tiende a la dispersión de los grupos en conflicto para mantenerlos independientes. 
De la interacción de estas fuerzas y de mayor o menor dominio de una u otra, emerge un proceso de conversión que se manifiesta a niveles distintos de integración o asociación.

Para Aguirre Beltrán, la conversión paralela es el más bajo nivel de integración que se presenta entre dos sociedades en contacto que son autosuficientes y autocontenidas. Esta conversión se denomina como paralela porque se trata de dos grupos que "marchan por caminos paralelos sin llegar a conjugarse, al favor de un entendimiento que desarrolla un sistema de relaciones posicionales basado en la mutua desconfianza, que las mantiene separadas" (Aguirre, 1957:47).

Otro tipo de conversión, es la alternativa. En ésta los individuos pasan a formar parte de la estructura social del grupo opuesto, en posición de inferioridad, cuando se trata de individuos procedentes de la sociedad bajo asedio y en una relación posicional inversa, en el caso contrario.

La conversión polar, por su parte, es aquélla en la que los grupos en contacto han alcanzado a construir una estructura social donde la interdependencia creciente de los grupos en simbiosis ha llegado al grado de convertirlos en uno solo (Aguirre, 1957:47).

En cuanto a estas relaciones de interdependencia que se establecen entre los grupos interactuantes que conviven en un mismo territorio podemos observar por un lado, el caso de las relaciones interétnicas dentro del contingente migratorio y por otro, el caso de las relaciones entre indígenas migrantes y no indígenas que residen en la zona receptora.

El origen del flujo migratorio es principalmente mixteco(63\%), el resto es de origen étnico muy heterogéneo, siguiendo en importancia numérica los zapotecos, los triquis, los nahuas y los tarascos. Entre el grueso de la población, los mixtecos -y los otros grupos indígenas-, a pesar de compartir una misma situación social y de estar inscritos en una misma clase social, los niveles de integración son variados, incluso entre los mismos mixtecos, influyendo en esto el pasado histórico.

Se sabe que los mixtecos constituían un grupo guerrero desde antes de la conquista, y que desde entonces, entre los principados que gobernaban respectivas áreas de la Mixteca se habían desarrollado rivalidades internas (Ravicz,1965); estos conflictos se multiplicaron o agudizaron con la presencia del colonizador y se proyectaron a la sociedad mixteca actual: "la gente de la costa afirma que los pobladores del valle y la montaña son sucios, visten pobremente y están poseídos por los brujos. La gente de las tierras altas dice que los de la costa son traidores y ladrones. En la Mixteca Alta y en la Baja están muy difundidas las historias acerca de la libertad sexual de las mujeres de la Costa, ligadas tales historias a la hechicería y a los encantamientos" (Ravicz,1965:36). ${ }^{5}$ 
Incluso, según el mismo Ravicz:

Dentro de una misma zona, la gente de un pueblo acusa a la del pueblo vecino de tener intenciones malévolas. Los habitantes de un pueblo se dan prisa al cruzar otro pueblo durante un viaje y todos llevan un arma oculta, generalmente una pistola. Las acusaciones de maldad se refieren no sólo a los individuos, sino al pueblo entero. Muchos incidentes violentos tienen lugar y sirven para reforzar esta creencia.(1965:36)

Por esta razón, en San Quintín, entre los indígenas migrantes de origen mixteco procedentes de distintos pueblos, existe una desconfianza latente; sin embargo, si bien esta desconfianza obstaculiza en cierta medida el trabajo de organización, no se desarrolla hasta adquirir la categoría de conflicto, debido a que, ante las diferencias con los otros grupos étnicos con los que tienen que interactuar en un mismo campamento e incluso en un mismo cuarto, el sentimiento de identidad de los mixtecos se ve reforzado al descubrir que son portadores de una misma cultura que los hace distintos; teniendo lugar entre los mixtecos de distintos pueblos, una conversión polar, por lo menos durante la migración, pues han adquirido un nivel de integración tal que han llegado al grado de convertirse en uno solo, a pesar de sus diferencias (Aguirre, 1957:47).

Esto mismo sucede entre mixtecos y zapotecos en San Quintín. Y es que antes de la llegada de los españoles a Oaxaca, los mixtecos invadieron a los zapotecos y posteriormente unidos hicieron frente a la invasión de los aztecas. Finalmente, la conquista de éstos sobre aquéllos se consumó, y zapotecos y mixtecos, ante una misma situación de dominación y un enemigo común, desarrollaron estrechos vínculos, pese a que conservan idiomas diferentes.

Dentro de esta misma conversión polar podemos ubicar la relación que se establece dentro de los campamentos entre mixtecos y los otros grupos étnicos,exceptuando a los triquis, ya que si bien se trata de grupos con orígenes e idiomas distintos, comparten una misma situación social, no tienen fronteras territoriales en conflicto en sus lugares de origen, y no han heredado antiguas pugnas.

La relación entre triquis y mixtecos sin embargo, resulta conflictiva, así como la relación entre triquis y los demás grupos étnicos que componen el flujo migratorio. El origen de esto lo podemos encontrar en la historia reciente y en sus pueblos, pues como lo afirma Fernando Benítez, ahí tiene lugar la guerra de los triquis.

5 Acerca de esta idea sobre la mujer de la costa puede leerse el relato contado por Julio Ramírez Ruiz, en la investigación original; Mixtecos, en Baja California: 223. 
Si es dificil pensar que en el México de nuestros días hay una guerra, aún resulta más dificil pensar en el conjunto de atroces circunstancias que la alimentan desde hace 20 años. Se trata de una pequeña guerra, de una guerra diminuta si se quiere, pero esta guerra existe con sus muertos, sus crueldades inauditas y las leyendas, las historias fantásticas y los terribles episodios propios de toda guerra"(Benítez,1967:T.I,422).

Esta guerra, como la llama Benítez, tiene su raíz en los problemas de tierras, pues las que corresponden a los triquis no están deslindadas ni mucho menos adjudicadas a sus legítimos propietarios; situación que aprovechan los mestizos para invadir las mejores porciones alimentando las rencillas entre indígenas. La falta de linderos bien definidos entre los pueblos coloca a los triquis ante una situación desventajosa ya que se encuentran rodeados de pueblos mixtecos, el principal de ellos es Juxtlahuaca.

Por ello, al marchar por caminos paralelos sin llegar a conjugarse, al favor de un entendimiento que desarrolla un sistema de relaciones posicionales basado en la mutua desconfianza, que las mantiene separadas (Aguirre,1957:47), la relación entre mixtecos y triquis se ubica dentro de una conversión paralela.

Entre los indígenas migrantes residentes, de cualquier origen étnico, existe una tendencia a la integración definitiva a la sociedad anfitriona, desechando pautas culturales que consideran obstáculo para dicha integración, dejando de transmitir su idioma materno a los hijos y adoptando la racionalidad mestiza, así como los hábitos consumistas y la búsqueda de reconocimiento entre el mundo no indígena; tal es su necesidad de supervivencia, que el ser indio les resulta una dificultad para sobrevivir y algunos están dispuestos a dejar de serlo, incluso, sirviendo de instrumento para el control de los otros indígenas. El caso de los camperos, ${ }^{6}$ es un dramático ejemplo de este tipo de integración, aunque también aquí pueden ubicarse los líderes sindicales que se encuentran pendientes de la situación social de los jornaleros, y aquella parte de los migrantes que se desenvuelven como vendedores ambulantes o jornaleros y que sin ser instrumento ni líder lleva a cabo su vida consolidando junto con los camperos y líderes, un tipo de conversión alternativa, en la que pasan a formar parte de la estructura social del grupo opuesto; en posición de inferioridad, cuando se trata de individuos procedentes de la sociedad bajo asedio (Aguirre,1957:47).

6 Comisarios de origen indígena que son contratados por los productores para vigilar los compamentos, y que frecuentemente maltratan a sus paisanos. 
Gonzalo Aguirre Beltrán considera que el enfoque cultural y el social no son excluyentes sino complementarios, ya que sin embargo, de la utilidad del enfoque social, su uso exclusivo hace perder una suma de cualidades trascendentes que sólo puede suministrar el enfoque cultural. La oposición y mutua exclusión de lo cultural y lo social es insostenible en la práctica y se resuelve, ineludiblemente, en la integración sociocultural que la supera (1957:48).

La forma en que se presentan los niveles de adaptación cultural y de integración social entre los distintos grupos migrantes en San Quintín, podemos sintetizarla en el siguiente cuadro:

\section{CUADRO 3. Niveles de adaptación y conversión.}

Adaptación

1)Comensal:

Proletarios que no emigran.

2)Selectiva:

Proletarios migrantes con retorno.

3)Sincrética:

Proletarios migrantes definitivos.
Conversión

1)Paralela:

Mixtecos y triquis residentes o con retomo.

2)Alternativa:

Mixtecos residentes y mestizos.

3)Polar:

Mixtecos y zapotecos.

\section{CONSIDERACIONES FINALES}

Ante la situación que viven los jornaleros indígenas en San Quintín, instituciones de gobierno, organizaciones sindicales, organismos asistenciales financiados por particulares norteamericanos y sectas religiosas, han acudido a tratar de resolver sus problemas más apremiantes, implementando estrategias diferentes y en ocasiones opuestas.

Independientemente de sus siglas o de sus respectivas áreas de acción, sean instituciones oficiales y organizaciones sindicales ligadas al estado, o independientes de él, toda forma de trabajo hacia los migrantes indígenas en San Quintín se encuentra ante una disyuntiva: realizar trabajo asistencialista o trabajo organizativo.

Ambos tipos de trabajo parten del reconocimiento de problemas sociales agudos que tienden a evolucionar al grado de conflicto y a originar formas de organización más radicales de los mismos jornaleros; sin embargo, sus concepciones acerca de esto son diferentes. 
El asistencialismo pretende eliminar todo foco potencial de agitación y núcleos de posible conflicto, a través de paliativos que crean la sensación de que las necesidades más sentidas han sido satisfechas, reduciendo así los intentos de organización de los trabajadores indígenas.

El trabajo organizativo, por su parte, tiene como fin la satisfacción real de las necesidades, no sólo de las más sentidas, sino también de las verdaderamente trascendentes, a través de la organización autogestiva, valiéndose en ocasiones, del mismo conflicto.

Lógicamente la política de trabajo de toda institución o sindicato vinculado al estado, está diseñada desde arriba como asistencialista, que en el caso de las instituciones, se trata de una asistencia muy limitada, debido a sus exiguos recursos. $\mathrm{Y}$ en el caso de las organizaciones sindicales, tales como Confederación Nacional Campesina (CNC), Confederación de Trabajadores de México (CTM), Confederación Nacional de Organizaciones Populares(CNOP), a pesar de que tienen numerosos grupos de jornaleros afiliados, no cuentan realemente con ningún trabajo organizado, ya que su afiliación de trabajadores es forzosa. Sin embargo, aunque esto suceda, quienes se encuentran realizando el trabajo de campo tienen amplias posibilidades de dar un verdadero sentido organizativo a su quehacer. Gracias a ello, dentro del estado, los trabajadores del Instituto Nacional Indigenista y el Instituto Nacional para la Educación de los Adultos han demostrado preocupación por constituir una red de núcleos organizados en los camapamentos de migrantes; y fuera del cstado, la Central Independiente de Obreros Agrícolas y Campesinos (CIOAC), y su escisión encabezada por Benito García, han hecho lo suyo.

Ahora bien, a pesar de que la alternativa organizativa es la más viable para realizar un trabajo efectivo en la elevación de los niveles de vida de los migrantes en San Quintín, tanto la institucional como la independiente poseen un factor común que los acerca a la posición asistencialista: la idea de que para mejorar, los indios deben dejar de ser indios.

Los asistencialistas junto con los productores, plantean que el indígena está acostumbrado a vivir precariamente, y que por lo tanto, la única forma de sacarlos del atraso es mediante la educación y la inculcación de "buenos hábitos", propios de los no indígenas. Las instituciones que se ubican dentro de la alternativa asistencial, desarrollan la actividad que realizarían en cualquier comunidad mestiza, implementando formas de satisfacción de las necesidades de los indígenas migrantes, sin tomar en cuenta los patrones culturales de la etnia, lo que explica en parte el fracaso de sus programas. El sindicalismo independiente por su parte, impone fórmulas de elección democrática, de dirección y de movilización que utiliza cualquier organización de lucha en un contexto industrial no indígena, argumentando, 
desde una perspectiva marxista, que el capitalismo tiende a proletarizar toda forma de vida precapitalista —entre ellas la indígena-, para engendrar la vanguardia única de la revolución: el proletariado; arribando así a la conclusión de que la integración definitiva de los migrantes al capitalismo no sólo es algo irremediable, sino incluso deseable.

Creo que el trabajo con migrantes indígenas debe estructurarse sobre una estrategia organizativa-asistencial, que consista en alternar los programas de atención a los jornaleros con los objetivos de organización autogestiva, de tal forma que la organización sea la base para la realización efectiva de los programas, al mismo tiempo que el objetivo principal a alcanzar mediante la aplicación de los programas.

Así, en todos y cada uno de los programas debe perseguirse una experiencia organizativa, esto es, la constitución de núcleos de jornaleros que analicen y discutan sus propios problemas y actúen en consecuencia, lo cual necesariamente los conducirá de una posición organizativa-asistencial a una posición organizativa-sindical; único instrumento que el trabajador puede esgrimir en la defensa de sus derechos laborales.

\section{BIBLIOGRAFÍA}

AGUIRRE Beltrán, Gonzálo. 1957. El proceso de aculturación. Ediciones de La Casa Chata. México, D. F.

ARIZPE, Lourdes. 1985. Campesinado y migración. Editorial SEP-CULTURA. México, D.F.

BENDESKY y Rodríguez. 1986. Perfil regional y estructural. UNAM.

BENITEZ, Fernando. 1967. Los indios de México. Tomo I; Editorial Era; México, D.F.

BONFIL, Guillermo. 1982. De politicas culturales y politica cultural. Edición del Museo de Culturas Populares, SEP. México, D. F.

CÁRDENAS, Rafael. 1987. "Principales actividades productivas en el área de la jurisdicción de CODEREQ". Ponencia presentada en el I Simposium sobre Desarrollo Regional de San Quintín (mimeo); San Quintín, Baja California, México.

CODEREQ, Coordinadora para el desarrollo regional de San Quintín. 1987. "Informe 1987" (mimeo). San Quintín, Baja California.

CONEPO, Consejo Estatal de Población. 1985. "Migración temporal" (mimeo). Mexicali, Baja California.

DE OLIVEIRA, Orlandina y Claudio Stern. 1974. "Notas acerca de la teoría de las migraciones internas; aspectos sociológicos" (mimeo). Segundo Seminario de Especialización en Demografía. México, D.F. 
FAIRCHILD, Henry Pratt. 1949. Diccionario de sociología. Fondo de Cultura Económica. México, D.F.

GARDUÑO, Everardo, Morán Patricia yGarcía Efraín. 1991. Mixtecos en Baja California. UABC.

INEA, 1986. "Jornaleros agrícolas migrantes y sus familias" (mimeo). Mexico, D.F.

INI, 1987. "Diagnóstico preliminar sobre la situación socioeconómica de los jomaleros agrícolas de San Quintín, Baja California", (mimeo).

LEY FEDERAL DEL TRABAJO. 1983. Editores Mexicanos Unidos. México, D.F.

MENDEZ, Leticia Irene y Mercado. 1985. Migración. Decision involuntaria. Instituto Nacional Indigenista.

NOLASCO, Margarita. 1972. "Oaxaca indígena" (mimeo). Instituto de Investigaciones e Integración Social del Estado de Oaxaca. Oaxaca, Oaxaca.

NOLASCO, Margarita. 1980. Aspectos sociales de la migracion en Mexico. T. II. SEP-INAH.

RAVICZ, S. Robert. 1965. Organización social de los mixtecos. Ediciones del Instituto Nacional Indigenista. México, D.F.

REWIS, Ruth y Vigorito Raúl. 1979. Transnacionales en América Latina. El complejo de frutas y legumbres en México. Editorial Nueva Imagen. México, D.F.

SARH, 1986. "Programa de desarrollo rural" (mimeo). Mexicali, Baja California.

SINGER, Paul. 1983. Migraciones internas: consideraciones tebricas sobre su estudio. Editorial Siglo XXI. México, D.F.

SHCP, Secretaría de Hacienda y Crédito Público. 1972. IX Censo general de población. México, D.F.

STAVENHAGEN, Rodolfo. 1978. Clase, etnia y comunidad; INI; 30 años después; Ediciones del Instituto Nacional Indigenista. México, D.F.

STERN, Claudio y Fernando Cortez. 1977. "Hacia un modelo explicativo de las diferencias interregionales en los volúmenes de migración a la ciudad de México, 1900-1970" (mimeo); ClAcso; México,D.F.

TOSCANO, M. Alejandro. Julio, 1979. "Memorias sobre investigación demográfica en México". NEXOS. No.19.

\section{PERIÓDICOS:}

La Voz De La Frontera. 20 de enero 1988. "Sobreexplotación de agua en San Quintín reconoce la SARH". 